\title{
Curriculum Evaluation and Transformation: Policies, Perspectives and Challenges
}

\author{
Matthew C. Stafford \\ Academic Administrator for US Air Force and Developmental Policy Author for US Department of Defense
}

\section{How to cite}

Stafford, M. C. (2019). Curriculum Evaluation and Transformation: Policies, Perspectives and Challenges. Asia Pacific Journal on Curriculum Studies, 2(1), 19-27. https://doi.org/10.53420/apjcs.2019.3

\begin{abstract}
To date, the vast majority of developmental programs have had to be satisfied with assessing students' learning within the confines of their programs. Although there were opportunities for indirect assessments, with graduate surveys or surveys of supervisors/employers, response rates tended to be low. Even when responses were received, they often came from people with little expertise in learning, making it difficult for educators to translate the feedback into actionable program improvements. The United States (US) Air Force has, however, decided to attempt what other learning institutions have not - arguably cannot. It is attempting to leverage its competency-based approach to performance assessment to enhance program evaluation. Because of the closed nature of this learning environment, where students graduate from US Air Force programs and go on to work in US Air Force jobs, there is a unique opportunity to assess learning as it is actually being applied in the workplace. Leveraging a competency-based force-development paradigm, the US Air Force has constructed a "foundational competencies" model for common knowledge, skills and abilities, complemented by occupational competencies specific to individual jobs, positions and specialties. These competencies are mapped to performance descriptions that determine levels of mastery. These performance descriptions are, in turn, mapped to rubrics that guide performance evaluations. Shortcomings in performance can be identified, quantified, and fed back to the developmental program for potential program modification or, for special updates to the force, to ensure Airmen perform their duties properly and achieve desired levels of mastery. This approach has been approved but is not yet fully implemented. The new Foundational Competencies Model has been developed and validated through a criterionsampling methodology. In addition, many technical careers have created "occupational competencies" models delineated the specific knowledge, skills and abilities specific to their jobs. The full range of supporting assessment mechanisms, however, are still in the process of being designed and dispatched to facilitate ease of use and centralize data-gathering. This article overviews the US Air Force's approach and its progress to date.
\end{abstract}

Keywords: curriculum evaluation, foundational competencies model, occupational competencies

\section{Introduction}

To date, the vast majority of developmental programs have had to be satisfied with assessing students' learning within the confines of their programs. Although there were opportunities for indirect assessments, with graduate surveys or surveys of supervisors/employers, response rates tended to be low. Even when responses were received they often came from people with little expertise in learning, making it difficult for educators to translate the feedback into actionable program improvements. The United States (US) Air Force has, however, decided to attempt what other learning institutions have not - arguably cannot. It is attempting to leverage its competency-based approach to performance assessment to enhance program evaluation.

Because of the closed nature of this learning environment, where students graduate from US Air Force programs and go on to work in US Air Force jobs, there is a unique opportunity to assess learning as it is actually being applied in the workplace. Leveraging a competency-based force-development paradigm, the US Air Force has constructed a "foundational competencies" model for common knowledge, skills and abilities, complemented by occupational competencies specific to individual jobs, positions and specialties. These competencies are mapped to performance descriptions that determine levels of mastery. These performance descriptions are, in turn, mapped to rubrics that guide performance evaluations. Shortcomings in performance can be identified, quantified, and fed back to the developmental program for potential program modification or, for special updates to the force, to ensure Airmen perform their duties properly and achieve desired levels of mastery. 
Program assessment is vital to the success of institutional learning objectives. Educators have leveraged assessments: to assist participants in the learning process; to make decisions on learner advancement; and to adjust program design, development and delivery to better meet stakeholders' needs.

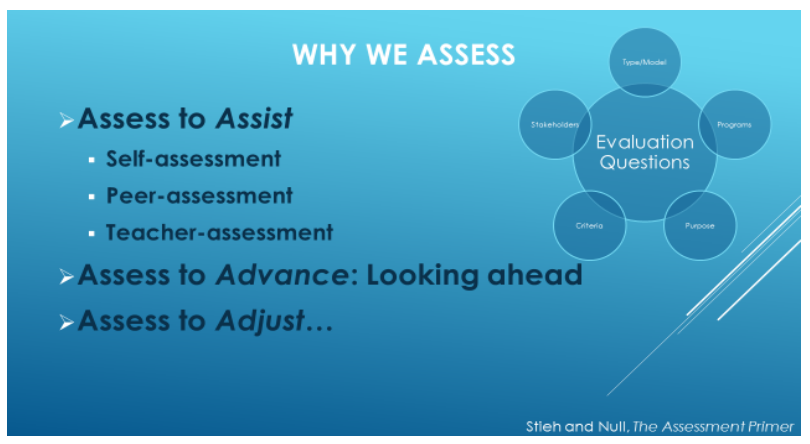

Figure 1. Why we assess

To Assist: The program-assessment tools educators have leveraged to assist participants have typically included self-assessments, peer assessments and teacher assessments. Although these can be helpful mechanisms, feedback is often highly subjective. Narrative descriptions of shortcomings can be difficult for curriculum designers to decipher, often leading to guessing as to exactly how programs might be improved to enhance learning. The US Air Force has leveraged such assessments for many year, in a variety of forms.

Graduate feedback, solicited from gaining-unit supervisors, however, is often imprecise, if it is received at all. The US Air Force has attempted to supplement this data with periodic conferences of subject-matter experts; however, this too can prove problematic both in terms of the clarity of the feedback and its timeliness to the programmatic needs.

To Advance: Advancement assessments, to include both formative and summative assessments, are invaluable tools that faculty members employ to determine whether learners are ready to proceed in or complete their learning programs. The US Air Force relies heavily on assessments of this nature in its technical-training programs. Instruction is divided into "blocks" and learners are typically prevented from progressing until a block is mastered. Its educational programs are not as structured, though one can find formative and summative assessments here as well.

To Adjust: Like most learning organizations, the US Air Force leverages assessments to adjust its training and education programs to meet its learning needs. Changes tend to be incremental over time and typically focus more on refining existing approaches and methodologies than on defining and developing toward new requirements. There are exceptions, of course. Rapid progress in learning technologies have brought about some excellent innovations in some US Air Force distance-learning programs; however, these have not yet been adopted universally as of this writing. In terms of curriculum content, one can cite examples where US Air Force programs have created new classes, courses and programs to meet specific needs; however, refinement tends to be the norm when reviewing the use of program assessment for adjustments in this military branch.

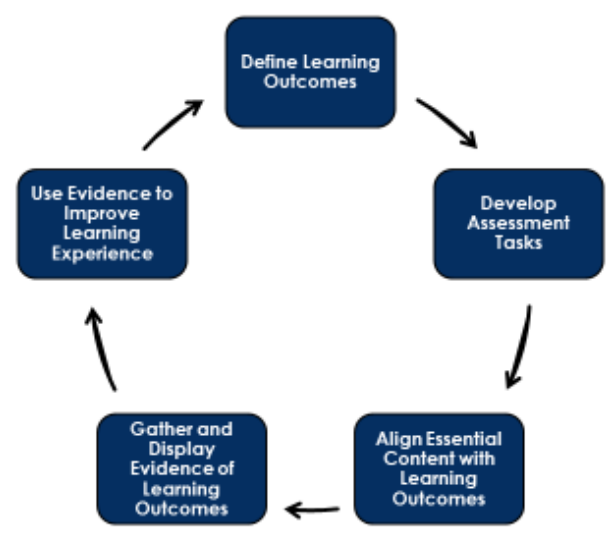

Figure 2. Assessing to adjust. 
The reliance on program assessment to assist, advance and adjust will continue with the implementation of competency-based learning; however, the US Air Force is learning that there are some exciting new opportunities emerging with this change. These will be discussed in detail below.

\section{Past Approach to US Air Force Program Assessment}

In the past, the US Air Force leveraged self-assessments, peer-assessments, and faculty assessments to assist learners in identifying strengths and weaknesses and leveraging a variety of tools to improve learning performance. Practice tests, skills tests, proficiency demonstrations, "practice rides," and a variety of other such assessments provided learners opportunities to measure their learning progress and adjust their performance or seek assistance as necessary.

As noted previously, however, these "assessments to assist" remained entirely within the self-contained learning program. A shortcoming in knowledge, skills or abilities that was not caught and corrected during the program but uncovered later in actual job performance, went largely unknown. Even when discovered, however, there was little chance the learning program could assist in correcting the shortcoming unless it was determined that it arose from some programmatic shortcoming. Only then might there be some program modification to ensure future graduates performed satisfactorily.

Another shortcoming of the historical approach was the absence of a standard "language" across the learning paradigm. If an Airman had difficulties with an electronics course, for instance, it might go unnoticed that the same Airman was experiencing difficulties in other areas, as there was no common vernacular to address related performance issues.

In terms of the "assessments to adjust," the US Air Force has relied heavily on the Kirkpatrick and Logic Models in its programassessment strategy. The Kirkpatrick Model is visible in virtually all of the US Air Force technical training programs, and the Logic Model underpins much of the curriculum design and development in the Service's educational programs. These two models should be familiar to readers; however, the two figures below provide a brief review.

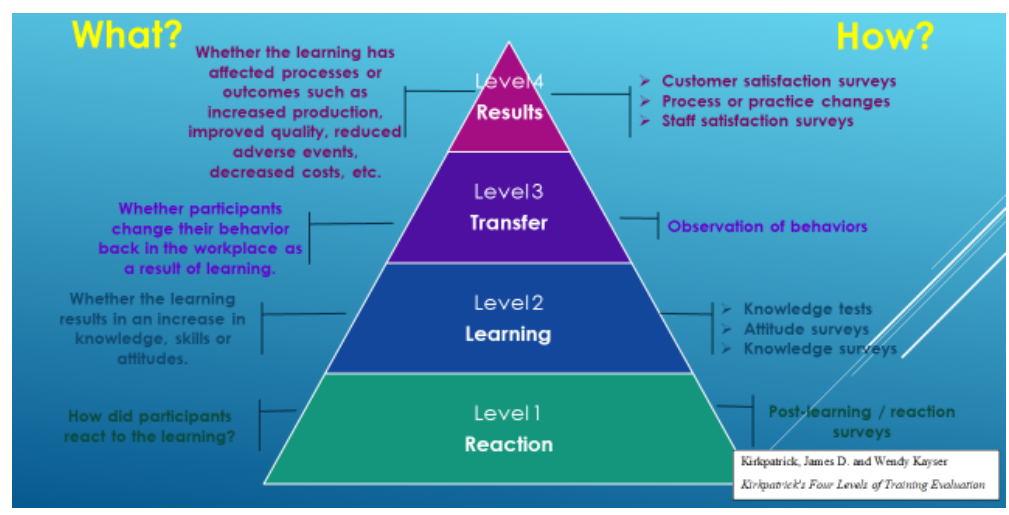

Figure 3. The 4-Level Kirkpatrick Model.

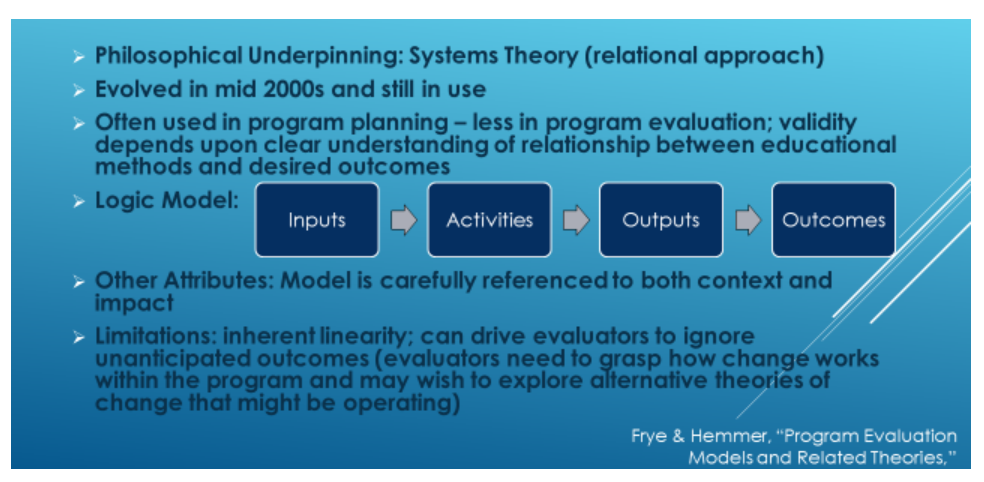

Figure 4. The Logic Model. 


\section{Leveraging Competency-Based Learning to Enhance Program Assessment}

Beginning in 2015, the US Air Force began an effort to revise its approach to learning. Its Air Education and Training Command, responsible for all of the Service's technical training, pilot training and professional military education program - virtually every formal developmental efforts save for the US Air Force Academy - launched an effort to determine those competencies that were most essential to Airmen's success.

Competencies were not new to the Service. A previous effort, launched at the Headquarters, US Air Force level, resulted in an "institutional competencies list." The list was valuable but was never fully implemented in terms of driving the Service's education and training programs nor in measuring program and personal effectiveness. The subsequent effort was different.

Firstly, the recent effort looked at competencies more holistically. Instead of simply knowledge, skills and abilities, this effort considered additional characteristics that would influence resulting performance. The pioneering work of Spencer and Spencer (Competence at Work: Models for Superior Performance [1993]) served as a foundation for the Service's research, development and validation efforts.

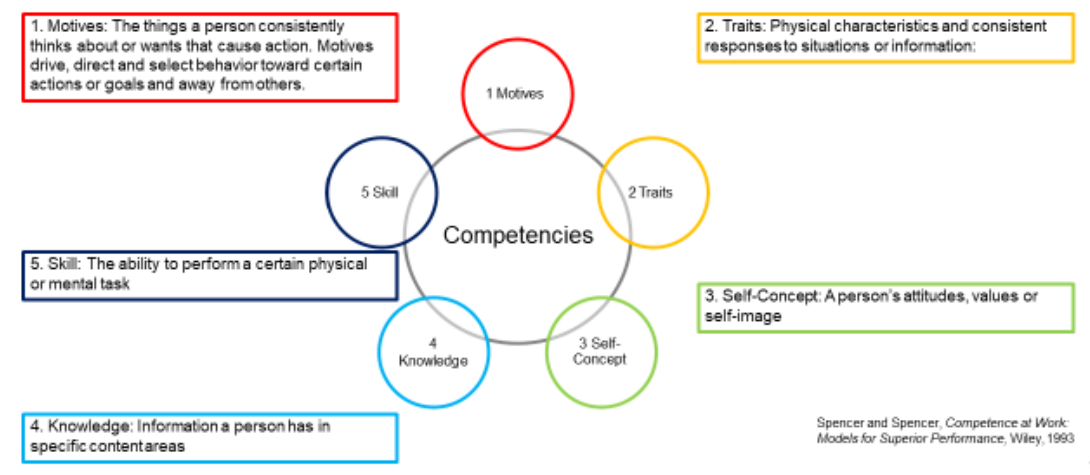

Figure 5. Competency characteristics

Leveraging contemporary research into competency-based learning, the US Air Force began to study the manner in which these various characteristics influenced performance and the ways in which its programs and various living and working opportunities could influence those characteristics. It was a far more holistic approach to learning than the Service had considered previously. Lucia and Lepsinger's "competency pyramid" figured prominently in this reconsideration.

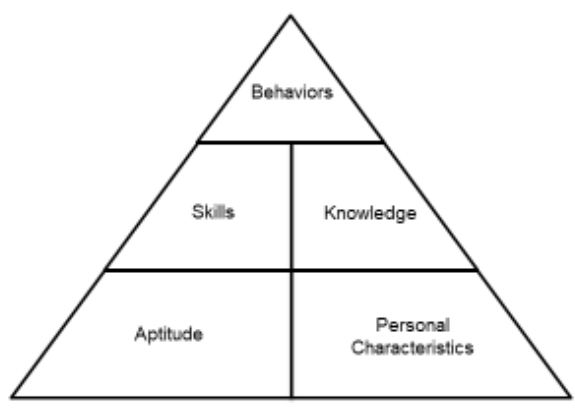

Figure 6. The Competency Pyramid. 
Those charged with this work were also careful to note advice from Seema Sanghi's The Handbook of Competency Mapping: Like icebergs, only the behaviors are visible; the rest of the factors are hidden within learners. Consequently, the Service directed its assessment attention to those behaviors.

Following extensive review and validation work, the US Air Force published its new Foundational Competencies Model in 2020.

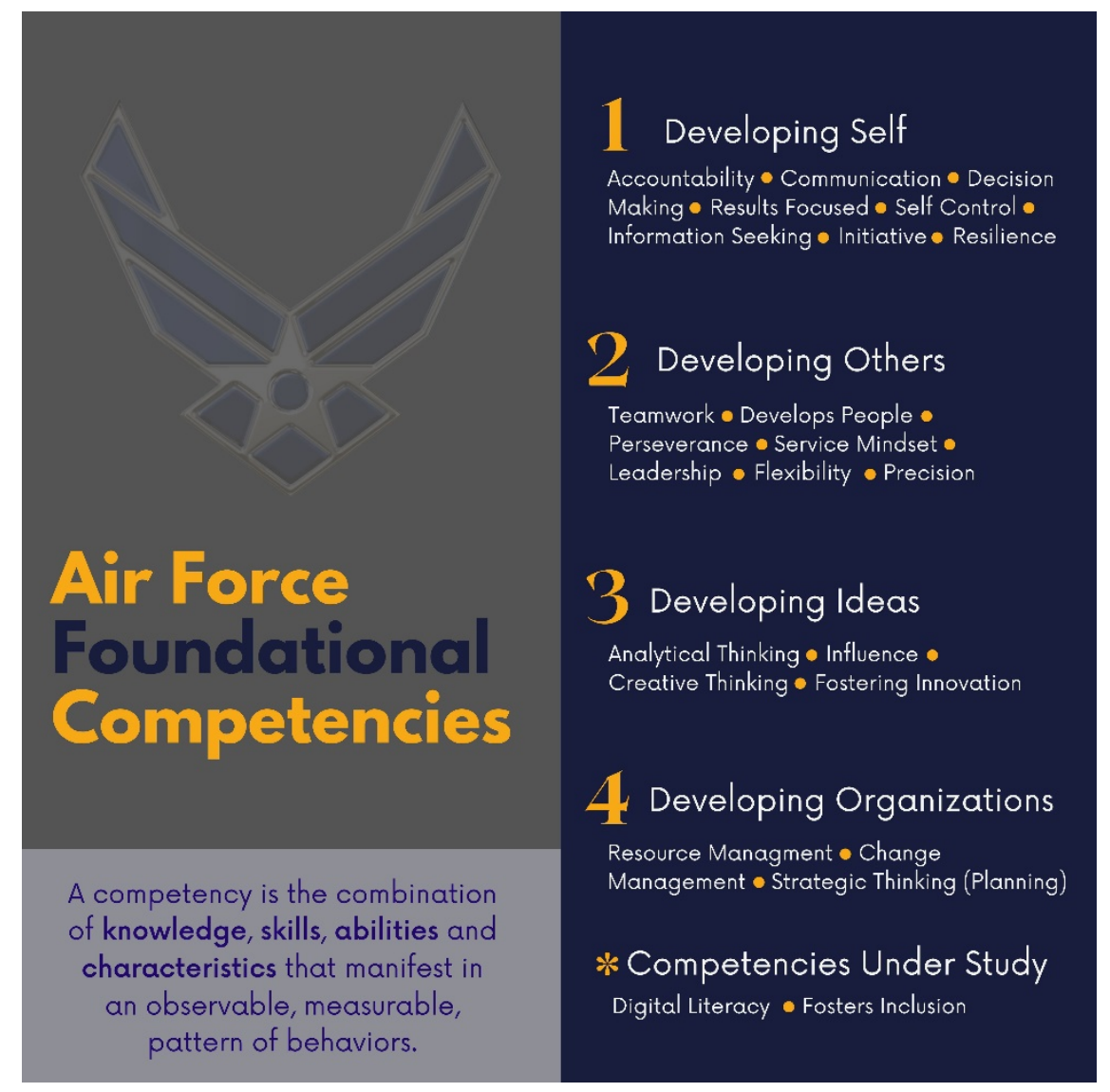

Figure 7. The Air Force Foundational Competencies Model.

Then, with the release of this list, it began working on an implementation strategy. Not only were these new competencies designed to help curriculum designers create learning strategies and programs specific to these needs but the Service also wanted to leverage these competencies to enhance its assessments of learning. Because of the "closed system" nature of the Service, where Airmen learn how to perform and then actually perform within the same organization, the competencies create a common mechanism for assessing how learning is employed. Instead of attempting to certify mastery in the learning environment, that final determination of mastery could be passed to the workplace, with a corresponding feedback mechanism to alert learning programs of needed improvements. This, obviously, required some supporting mechanisms.

Although the first step was completed, with the issuance of the Foundational Competencies, the development team next had to describe the performance levels. The Service described these as "levels of mastery," which evolved through five stages, from "Novice" through "Master." These stages are visible in Figure 8, below. Each of these stages of mastery was captured in a narrative. Next, the developmental team began constructing assessment rubrics so observers could make objective judgments as to the level of mastery learners had achieved. These were built in concert with the assessment mechanisms; the tools that would actually be employed to assess learners' mastery. 


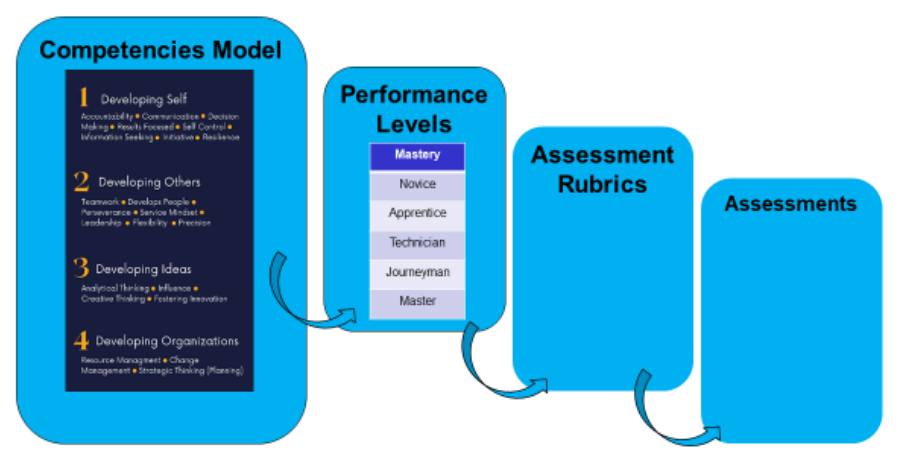

Figure 8. Validation and Implementation of US Air Force Competencies Model.

Some of the competencies are difficult to describe. The developmental team consulted the available research, conducted interviews and surveys, then validated its results through a variety of scored surveys. The example below provides a notional example of one of the competencies that was approved and corresponding levels of mastery. ${ }^{1}$

Table 1

Notional Description of "Develops People” Competency and Related Mastery Levels

\begin{tabular}{|c|c|c|c|c|c|}
\hline & Novice & Apprentice & Technician & Journeyman & Master \\
\hline $\begin{array}{l}\text { Helping others } \\
\text { reach their } \\
\text { maximum } \\
\text { potential; } \\
\text { investing in others } \\
\text { to maximize their } \\
\text { contributions to } \\
\text { the mission by } \\
\text { inspiring and } \\
\text { providing an } \\
\text { environment of } \\
\text { continual } \\
\text { feedback and } \\
\text { learning } \\
\text { opportunities. }\end{array}$ & $\begin{array}{l}\text { Explains personal } \\
\text { contributions and } \\
\text { differentiates } \\
\text { other's } \\
\text { contributions to } \\
\text { group } \\
\text { effectiveness. } \\
\text { Demonstrates } \\
\text { responsibility to } \\
\text { help and motivate } \\
\text { others to improve } \\
\text { their skills and } \\
\text { enhance their } \\
\text { performance } \\
\text { through personal } \\
\text { example. }\end{array}$ & $\begin{array}{l}\text { Diagnoses } \\
\text { capability and } \\
\text { developmental } \\
\text { needs. Plans and } \\
\text { supports } \\
\text { deliberate } \\
\text { development of } \\
\text { individuals' skills } \\
\text { and abilities } \\
\text { through setting } \\
\text { and monitoring } \\
\text { development } \\
\text { plans, identifying } \\
\text { and securing } \\
\text { resources to } \\
\text { enable person to } \\
\text { fulfill current or } \\
\text { future job/role } \\
\text { responsibilities } \\
\text { more effectively. }\end{array}$ & $\begin{array}{l}\text { Facilitates others } \\
\text { and guides them } \\
\text { in establishing } \\
\text { their long term } \\
\text { career goals based } \\
\text { upon their desires } \\
\text { and the needs of } \\
\text { the Air Force } \\
\text { through a } \\
\text { combined } \\
\text { approach of } \\
\text { feedback, } \\
\text { coaching, } \\
\text { mentoring, and } \\
\text { delegating. }\end{array}$ & $\begin{array}{l}\text { Evaluates and } \\
\text { selects talent to } \\
\text { ensure the best } \\
\text { match between } \\
\text { the individual and } \\
\text { the work } \\
\text { requirements. } \\
\text { Determines the } \\
\text { mix and level of } \\
\text { capability across } \\
\text { subordinates } \\
\text { required to } \\
\text { support current } \\
\text { and future goals } \\
\text { and mission. }\end{array}$ & $\begin{array}{l}\text { Supports, } \\
\text { recommends or } \\
\text { implements talent } \\
\text { management } \\
\text { systems that } \\
\text { create a learning } \\
\text { culture and } \\
\text { inspires others to } \\
\text { transcend their } \\
\text { own self-interests } \\
\text { for the good of the } \\
\text { mission and } \\
\text { organization. } \\
\text { Aligns systems to } \\
\text { support a learning } \\
\text { culture. } \\
\text { Establishes } \\
\text { adequate } \\
\text { development } \\
\text { resources as } \\
\text { needed. }\end{array}$ \\
\hline
\end{tabular}

The developmental team next had to take these tables and construct assessment rubrics and mechanisms so faculty members and later, supervisors, could employ them to gauge learners' levels of mastery. This work is ongoing, however, referring back to the competency "Develops People," here is how such an assessment mechanism might work.

The Airman being assessed might be challenged to teach a new skill to others (the assessment mechanism). The rubric would address the manner in which the Airman shared the underlying knowledge, demonstrated the task, provided feedback on the task, determined the others' level of success, and the degree to which the others were further encouraged to continue learning. This is not so different from what schools do in terms of assessing learners' performance. What is different with the US Air Force approach is that supervisors are being equipped to make these assessments and, with the tools provided, have a mechanism to

\footnotetext{
${ }^{1}$ Note: This example originated in the early research-and-development work. It may vary from the final, approved form.
} 
report that data back to the learning institutions for program adjustment. Actual job performance becomes part of the learning institution's assessment strategy. In essence, the US Air Force seeks to expand the assessment loop depicted in Figure 1:

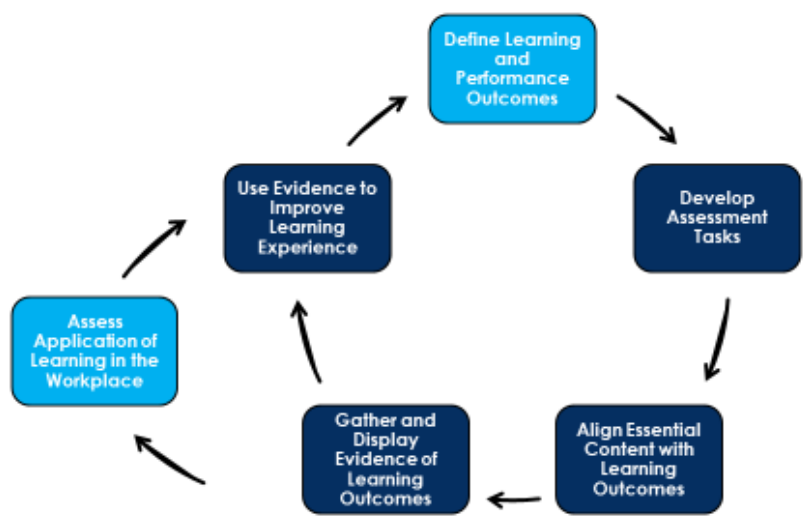

Figure 9. Expanding the Assessment Loop.

The Service aims to automate these assessments. Doing so will make them easier for supervisors to use and increase both the quality (usability) and quantity of the feedback the learning institutions receive. Although this will be valuable in technicaltraining situations, it will prove revolutionary for educational programs.

Competencies involving interpersonal activities are very difficult to simulate in the classroom. Even one-on-one activities, such as coaching and counseling, are difficult to simulate, if only because the learning environment is so artificial. By assessing these competencies in the workplace, the Service can get a much better view of its Airmen's actual level of mastery in these vital "people competencies." Further, actual certification of appropriate levels of mastery can be off-loaded from the learning institution to the supervisors and certifiers in the workplace; those who have the most to gain or lose as a result of a learner's level of mastery.

Another important use of these tools is self-assessment. The US Air Force has gone into this effort with the firm belief that it must be transparent in the use of its competency-assessment tools. This means sharing the competencies, descriptions, mastery levels, and rubrics with its Airmen. Armed with these tools, Airmen can and should assess themselves. Not only does this allow Airmen to gauge their readiness for a supervisor's assessment but in many instances, it can help Airmen bypass unnecessary instruction to reach the workplace more quickly.

In the past, US Air Force developmental programs were time-based. Learners arrived on a given date, proceeded through a program with their peers - one block of instruction at a time - and graduated on another given date. As it moves to a competencybased approach, however, these programs are transforming. Airmen can review the required competencies and rubrics and, if they feel they are qualified in an area, request to "test out of" that instruction. A master computer programmer need not sit through introductory instruction on the use of a program. That master programmer can complete that associated assessments and move forward to a different learning area or, in some cases, report immediately to the job.

The US Air Force has allowed this for years in a few, very specific training areas such as piloting; however, the advent of competency-based learning is expanding this capability across the learning enterprise. In terms of professional military education, it is envisioned that an entering student who already possesses all of the knowledge and skills associated with a given course or block of instruction would instead pursue an area of mutual personal interest and Service need. Such an Airman might engage in a Headquarters-sponsored research effort or pursue job-related coursework at another learning institution. The goal of "not having to learn things you already know" is a popular one among Airmen. It is driving major challenges for the US Air Force talentmanagement system. As one might imagine, projecting training dates months and even years in advance simplifies the complex human capital-management equation considerably. Having students graduate at different times creates major headaches for assignment managers. Still, the Service's top personnelists has pledged to do all in his power to make this work.

Yet another benefit of this competency-based approach is the ability to conduct force-wide analysis. For the past decade, senior leaders of the US Department of Defense have labored to understand the complex challenges associated with "force readiness." 
When is a military member "ready?" When is a military unit "ready?" The Department has developed a variety of mechanisms aimed at assessing readiness but these have been fairly broad in their focus. Personnel readiness, for instance, has focused on the quantity of individuals, their rank, and their specific specialties, usually generalizing abilities based on these factors.

Competency-based assessments allow a granular understanding of the human element of force readiness. Leaders will not only know how many people they have in a given unit, but will also have insight into what these people know and what they can do. They will not have to guess at these capabilities, because everything that these people know and can do will have been demonstrated and certified in a competency-based assessment.

Equipped with this level of knowledge, Service leaders will be able to conduct force planning, programming and even future forecasting more accurately than in the past. Emerging technologies, requiring different skills and knowledge from that imparted in existing learning programs, can be added into the competency-based learning paradigm to create a properly skilled workforce more quickly. An example will serve to illustrate:

Suppose that a new computer technology is emerging - quantum computing. Under the old system, the Service would bring that capability into its school houses, put it into the curriculum, and months later, would begin delivering graduates capable of leveraging this technology. Under competency-based learning, the Service can turn to its competency-development teams to create or modify the specific competencies needed, the levels of mastery, and the assessment rubrics and mechanisms. It could then dispatch those descriptions and rubrics to the force, to see how many Airmen self-identified as possessing those abilities. Those Airmen claiming mastery would be assessed and, if their mastery were validated, leveraged to aid the US Air Force in developing curriculum, teaching others, or even beginning to leverage the new technology in support of operations.

It should surprise no one that people have knowledge and skills unknown to their employers. Workers have lives outside of their workplace. It is the same for military members. Many have studied in programs unrelated to their military careers, either before joining or through off-duty education programs. US Reservists and National Guard members have civilian jobs, often completely unrelated to their uniformed duties. Competency-based learning allows a mechanism that can be employed to discover and document additional skills and abilities workers and military members possess. Further, because disclosure is voluntary members have to request the assessments - this is neither intrusive nor unfair. It is merely a means for the Services to take advantage of the tremendous array of talent readily available within its ranks.

Of course, the current applications of feedback in learning-program management will continue; however, this more granulated understanding of graduates' performance in their workplaces will provide those designing and developing curriculum with far more data - and more actionable data than is available currently. Experts at every stage of the curriculum design and development process can access this data. They can even interact with the competency-design team to adjust workplace assessment rubrics and mechanisms to focus on specific areas of interest within their domains. In this way, these curriculum experts can explore different strategies in terms of what they will assess and leverage the returning data appropriately.

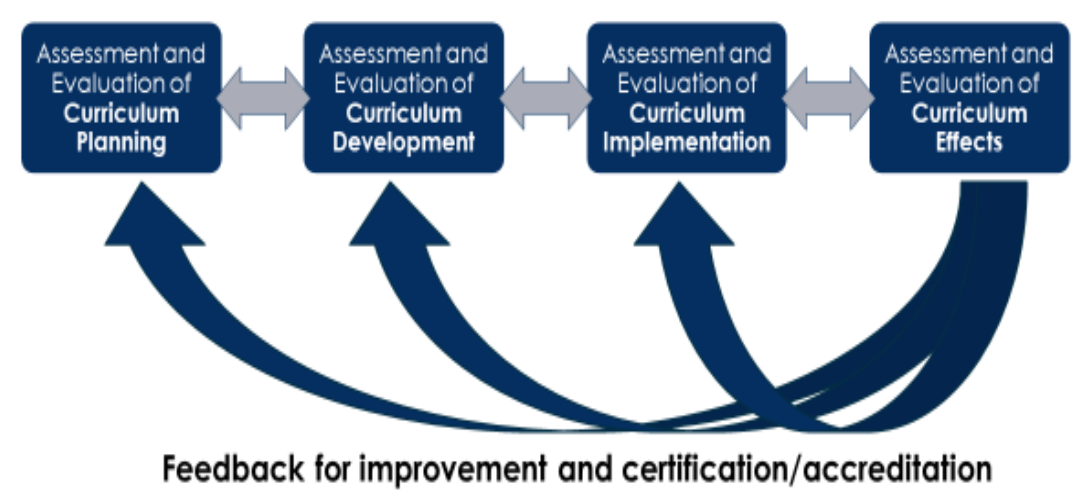

Figure 10. What to Assess and How Resulting Data Can Be Leveraged. 


\section{Summary}

Competency-based learning is not new, and neither is program assessment. The marriage of these two functions, coupled with the use of competency-based assessments in the workplace, presents exciting opportunities for capturing and leveraging performance data to enhance learning programs. By expanding the traditional feedback loop to make workplace supervisors an integral member of the performance-assessment team, curriculum experts will have expanded insights into the impact of their work. They will be able to tailor developmental investments more specifically to address learner needs both within their programs and in their follow-on careers.

Because of its unique environment - the fact that graduates of its learning programs remain in its workspaces for follow-on assessment - the US Air Force is in an excellent position to maximize the benefits of this interlaced approach. Non-military learning organizations can do the same; however. It takes close coordination with the appropriate work forces and employers but can achieve similar benefits for all involved.

\section{References}

Frye, A. W., \& Hemmer, P. A. (2012). Program evaluation models and related theories, AMEE Guide No. 67. Medical Teacher, 34(5), e288-99. https://doi.org/10.3109/0142159x.2012.668637

Kirkpatrick, J. D., \& Kayser, W. (2016). Kirkpatrick's Four Levels of Training Evaluation, Kirkpatrick(1st ed.). Association for Talent Development.

Ling, C. S., Seng, H. Y., Chi, L. C., Jaafar, T., Yi-Ling, T., Thangaraju, V. M., \& Woels, E. (2007). Exploring the Use of Evaluation Models to Inform Curriculum Planning and Development. APEC Conference on Evaluation as a Tool in Educational Planning: Best Practices in Evaluation of Educational Programs, 29 Oct. - 1 Nov. 2007.

Lucia, A. D., \& Lepsinger, R. (1999). The Art and Science of Competency Models: Pinpointing Critical Success Factors in Organizations. San Francisco: Jossey-Bass/Pfeiffer

Spencer, L. M., \& Spencer, S. M. (1993). Competence at work: Models for superior performance. New York: Wiley.

Telban, K., \& Stiehl, R. (2017). The Assessment Primer (Volume 2 of the Outcome Primers Series, 2.0. California: CreateSpace Independent Publishing Platform. 